\title{
129 A CRITIQUE OF THE NHS ADRT PROFORMA
}

10.1136/bmjspcare-2011-000053.129

J Martin, L Sallnow St Joseph's Hospice, Hackney, UK

At St Joseph's Hospice the process of documenting advance decisions to refuse treatment (ADRTs) has been shaped by patient and practitioner experiences. To guide this process the proforma available from the ARDTNHS website (http:// www.adrtnhs.co.uk) has historically been used. We present a critique of this document, reflecting broader issues concerning how ADRTs are recorded.

In order for ADRTs to be valid and applicable in the UK they should specify both the refusals and the circumstances in which they come into effect. If these exact circumstances do not occur the ADRT does not hold the legal refusal status it otherwise would, although it still might be used to inform decision making. We contend that a clinician's judgment is usually required to determine whether the ADRT circumstances really apply at the moment of decision. Our view is that refusals, and the circumstances in which they apply, can only be properly understood in the context of information that gives rationale and 'balance' to these decisions. In this way the intentions behind the ADRT can be used to interpret the refusals more accurately. This information (which might be found in a separate advance statement) is of such importance that it should be positioned ahead of the refusals in the same ADRT document. Examples will be used to illustrate these points. Successful ADRT documentation is not simple and requires balanced information. 